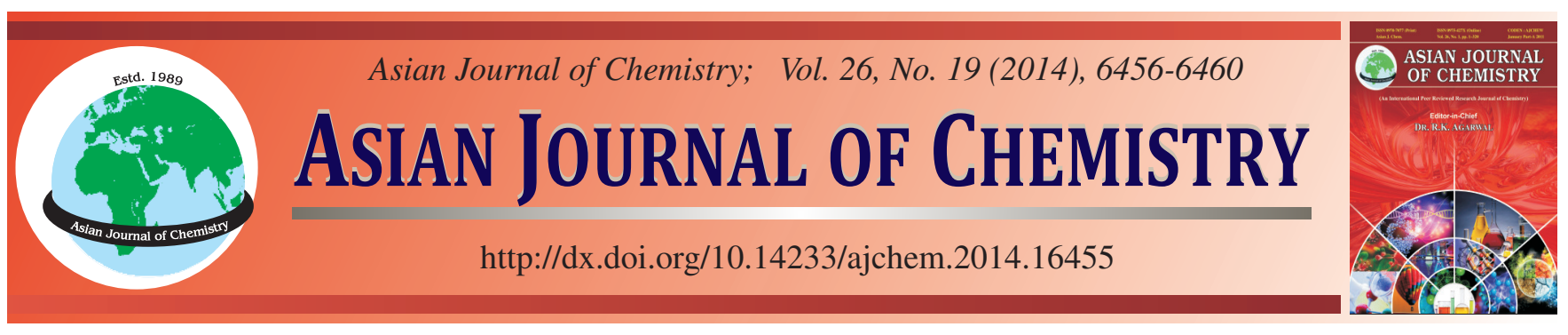

\title{
Determination of Carbamate and Triazol Pesticides in Soil Using QuEChERS with Liquid Chromatography-Tandem Mass Spectrometry
}

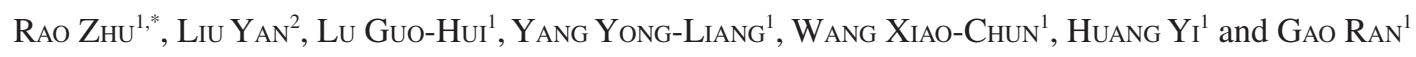

${ }^{1}$ National Research Center for Geoanalysis, Beijing 100037, P.R. China

${ }^{2}$ Beijing Labtech Instruments Co. Ltd., Beijing, 101312, P.R. China

*Corresponding author: Tel/Fax: +86 10 68999590, E-mail: raozhu@126.com

Received: 1 October 2013;

Accepted: 23 December 2013;

Published online: 16 September 2014;

AJC-15939

\begin{abstract}
A method for the simultaneous determination of 18 carbamate and triazol pesticides in soil using modified QuEChERS combined with liquid chromatography tandem mass spectrometry has been developed. The targets in soil were extracted by shaking extracted with acetone and dichloromethane and the extract was cleaned up by dispersive solid phase extraction, then analyzed by LC-MS-MS in the mode of multiple reactions monitoring with electrospray ionization source. Stable isotope internal standards were used for quantitative analysis. All the correlation coefficients of 18 targets were greater than 0.995 . The samples spiked recoveries at a concentration level of 1 $\mu \mathrm{g} / \mathrm{kg}$ and $10 \mu \mathrm{g} / \mathrm{kg}$ were from 64.9 to $94.2 \%$ and from 64.7 to $104.7 \%$, respectively with relative standard differences range from 1.98 through $16.83 \%(\mathrm{n}=8)$. The method detection limits ranged between 0.010 and $0.130 \mu \mathrm{g} / \mathrm{kg}$. The method is sensitive, simple, low-cost, fast and has been applied to detection of soil samples.
\end{abstract}

Keywords: Carbamate, Triazol pesticides, QuEChERS, Liquid chromatography-tandem mass.

\section{INTRODUCTION}

In the farming process, most of the pesticide has not been exploited by plants directly into the soil, causing the soil, air and water pollutions and creating potential threats on human health and the environment. Carbamate pesticides are a broadspectrum insecticide and widely used in farming with a high efficiency and short residual period. The triazole pesticides used has also increasing due to effect on crops pathogens and plant growth regulatory function. However, there are evidences that carbamates, triazole pesticides could have a potential health risk of toxicity on human endocrine, Meanwhile the vapour pressure of the carbamates and triazole are low, they will evaporate slowly at normal temperature, which may lead to easy to these residence in soil ${ }^{1-3}$. Therefore, it is necessary to be monitored for carbamate and triazole pesticides in soil.

The gas chromatography (GC) coupled to selective detection system, such as electron-capture detection, nitrogen-phosphorous detection or mass spectrometric detection or liquid chromatography (HPLC) are mainly analytical techniques for pesticides residues analysis ${ }^{4-9}$. GC and GC-MS are not suitable for determination of carbamate and triazole pesticides due to their polar, thermolabile and low vapour pressure, meanwhile HPLC is not also ideal tool for carbamate and triazole pesticide residues analysis because of analytical targets need to be derivatized with low sensitivity and accuracy. In recent years, the liquid chromatography-tandem mass spectrometry (LCMS-MS) continues to gain popularity for pesticide analysis with most applications focused on non-GC amenable compounds, thermolabile, polar and non-volatile pesticides ${ }^{10-12}$. So it is obvious advantages for carbamate and triazole pesticide residues analysis using LC-MS-MS that targets do not need to be derivatizaed with high sensitivity and accuracy and matrix interference resistance especially in the mode of multiple reaction monitoring (MRM).

However, the residue detection of carbamate and triazole pesticide mainly focus on those of in vegetables, fruits, grains, edible fungus and water at present ${ }^{4,5,9,10,12}$. The report of analysis of carbamate or triazole pesticide in soil is very few and of the simultaneous detection of two kinds of pesticides residue is less. This paper described that simultaneous determination of 18 kinds of carbamate and triazole pesticide along with their degradation products in soil samples by LC-MS-MS in multiple monitoring mode with modified QuEChERS method combined with matrix solid-phase dispersion to rapid extraction and cleanup, in addition to using isotope internal standard to improve quantitation accuracy and realize simple, fast and effective measure for the targets in soil. 


\section{EXPERIMENTAL}

Agilent 1200 Series HPLC, USA. API 4000 triple quadrupole mass spectrometer with electrospray ion source, $\mathrm{AB}$ SCIEX Co. Ltd, USA. $40 \mathrm{~mL}$ amber glass bottle with a Teflonlined film screw cap. The Carbamate dedicated liquid column $(4.6 \times 150 \mathrm{~mm} ; 5 \mu \mathrm{m}), \mathrm{C}_{18}$ liquid X-bridge $(2.1 \mathrm{~mm} \times 3.5 \mu \mathrm{m}$; $150 \mathrm{~mm})$ and the phenyl liquid column X-bridge $(2.1 \mathrm{~mm} \times$ $3.5 \mu \mathrm{m} ; 150 \mathrm{~mm}$ ) were purchased from the Waters Co. Ltd, USA.

Monomer stock standard solutions of 18 carbamates, triazole pesticides and their degradation products for certified reference materials at a concentration of $100 \mathrm{mg} \mathrm{L}^{-1}$, purchased from the Chemical Metrology \& Analytical Science Division, National Institute of Metrology. The carbaryl- $\mathrm{D}_{3}$, aldicarb- $\mathrm{D}_{3}$ and tebuconazole- $\mathrm{D}_{6}$ at a concentration of $100 \mathrm{mg} / \mathrm{L}$ used for the isotope internal standards (Germany, Dr. Ehrenstorfer company). Fluconazole-D 4 (Germany, Dr. Ehrenstorfer) and 4-bromo-3,5-xylyl-N-methyl carbamate (BDMC, J \& K Chemical Co., Ltd.) at a concentration of $100 \mathrm{mg} / \mathrm{L}$ used for surrogate standards. The all of standards should protect from light and stored at $-18{ }^{\circ} \mathrm{C}$. Formic acid and ammonium formate (excellent grade, Fluka Company), methanol and acetonitrile (HPLC grade, J \& K Chemical Co., Ltd.), acetone and methylene chloride (pesticide residues grade, J \& K Chemical Co., Ltd.). The soil samples were collected from grass, watermelon field, wheat field and peach orchard soil near to suburban areas of Beijing respectively and blank soil sample come from no pesticide pollutant soil.

Sample extraction: Weigh $5 \mathrm{~g}$ of soil sample into $40 \mathrm{~mL}$ amber glass bottle, add $10 \mu \mathrm{L}$ fluconazole- $\mathrm{D}_{4}$ and BDMC $(1 \mathrm{mg} / \mathrm{L})$ mix surrogate standard, $20 \mathrm{~mL}$ acetone-methylene chloride $(3: 1, \mathrm{~V}: \mathrm{V})$ mixture extract solvent. The sample bottle was shook for $60 \mathrm{mins}$ at 230 times/min in oscillator prior to centrifugation for $20 \mathrm{~min}$ at $3000 \mathrm{rpm}$, then $8 \mathrm{~mL}$ of the supernatant was transferred to $15 \mathrm{~mL}$ polypropylene centrifuge tube with $150 \mathrm{mg}$ PSA, $200 \mathrm{mg} \mathrm{GCB}$ and $500 \mathrm{mg}$ of anhydrous magnesium sulfate for cleanup.

Vortex polypropylene centrifuge tubes for $1 \mathrm{~min}$, centrifuged $20 \mathrm{~min}$ at $3000 \mathrm{rpm} .4 \mathrm{~mL}$ of the supernatant was evaporated to dryness using a gentle stream of nitrogen, restored volume to $1 \mathrm{~mL}$ with methanol-water $(1: 1, \mathrm{~V}: \mathrm{V})$, spiked 10 $\mu \mathrm{L}$ of Carbaryl- $\mathrm{D}_{3}$, aldicarb- $\mathrm{D}_{3}$, tebuconazole- $\mathrm{D}_{6}$ mix internal standard at the concentration of $1.0 \mathrm{mg} \mathrm{L}^{-1}$, then determined by LC-MS-MS after filtrating over $0.45 \mu \mathrm{m}$ PTFE membrane.

Analytical conditions: Waters carbamate dedicated analytical column $(4.6 \mathrm{~mm} \times 150 \mathrm{~mm} ; 5 \mu \mathrm{m})$, column temperature was set $30{ }^{\circ} \mathrm{C}$. Mobile phase is constituted of A phase water and $B$ phase methanol and its flow rate is of $0.3 \mathrm{~mL} / \mathrm{min}$, injection sample volume $40 \mu \mathrm{L}$. The gradient elution program: 0-2 min A and B was $50 \%, 2-6$ min A drop from 50 to $10 \%$, B to $90 \%, 6$ to 20 min each phase remains unchanged, 20-23 min A rise of $50 \%$, B reduced to $50 \%, 23$ to $30 \mathrm{~min}$ two phase remains unchanged.

Electrospray ion source temperature $400{ }^{\circ} \mathrm{C}$, positive ion ionization mode, electrospray ionization voltage IS $5000 \mathrm{~V}$, ion source collision gas CAD $68.9 \mathrm{kPa}$, curtain gas (CUR) $68.9 \mathrm{kPa}$, atomizing gas GS $137.9 \mathrm{kPa}$, multiple reaction monitoring mode (MRM).The monitoring ion pairs and mass spectrum parameters are shown in Table-1.

\section{RESULTS AND DISCUSSION}

Optimization of extraction conditions for soil sample: QuEChERS (quick, easy, cheap, effective, rugged and safe) is a new sample preparation method for determination of pesticides in fruits and vegetables and published recently as AOAC Method 2007.01, but rarely used in soil samples ${ }^{11-17}$. Its basic analytical procedure is that extracted homogenized samples with acetonitrile buffer solution, centrifuged and cleaned up sample extract by dispersive solid phase extraction and then the supernatant directly injected into LC-MS or GC-MS determination. This paper established a soil rapid extractive method base on QuEChERS, which the carbamates and their degradation products along with triazole pesticides in soil were extracted using shaking extract with organic solvent, the extract was cleaned up by matrix solid-phase dispersion, the supernatant after centrifugation were concentrated and then LCMS-MS detection., Respectively investigates single and mixed extractive solvent effect on the soil spiked recoveries such as the acetonitrile, methanol, acetonitrile-methanol (2:1, v/v), acetone, acetone-methylene chloride (3:1, v:v). The results optimized are given in Fig. 1. Fig. 1 shows that acetone extraction spiked recoveries of all the targets are generally low, methanol and acetonitrile-methanol mixed solvent of spiked recoveries are also low and acetonitrile spiked recoveries relatively large changes from 48.1 to $125.9 \%$ with the lowest of $48.1 \%$ for asaldicarb sulfone and exceeding $120 \%$ for three hydroxyl carbofuran, aldicarb sulfone, propiconazole and tebuconazole Hexaconazole, but acetone-methylene chloride mixed solvent spiked recoveries were in range of 65.2 to 113.9 $\%$ and meet the analytical requirement. Therefore the acetonemethylene chloride (3:1, v:v) was chosen as extractive solvent for extraction of the carbamates and triazole pesticides in soil. The matrix solid-phase dispersion with $150 \mathrm{mg}$ PSA, $200 \mathrm{mg}$ GCB and $500 \mathrm{mg}$ of anhydrous magnesium sulfate for cleanup sample is also simple and fast clean-up approaches for elimination or reduction of interferences of soil matrix. The soil QuEChERS method established overcomes thermal degradation of carbamate, triazole pesticidethe, low recoveries caused using traditional soil sample thermal extraction and realized rapid, easy, low-cost and effective preparation for soil samples.

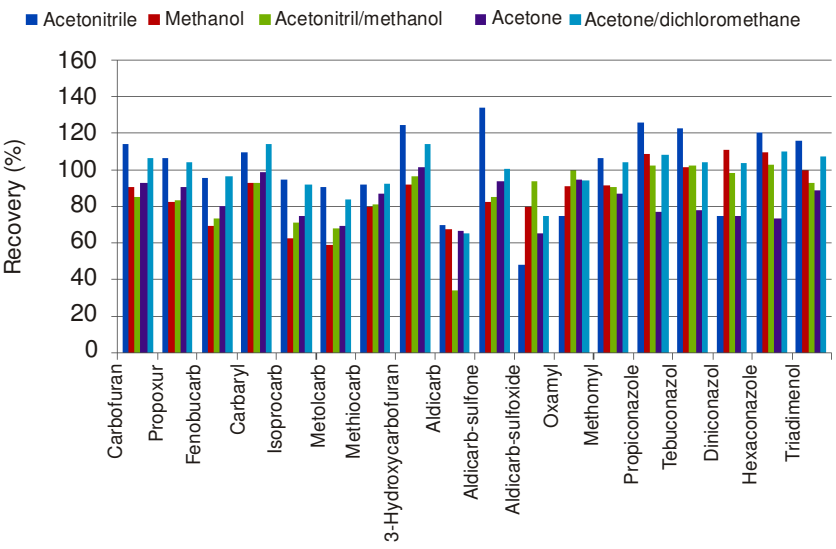

Fig. 1. Effect of the solvent of soil QuEChERS extraction on spiked recoveries of target compounds 


\begin{tabular}{|c|c|c|c|c|c|c|c|}
\hline \multicolumn{8}{|c|}{$\begin{array}{c}\text { TABLE-1 } \\
\text { MS PARAMETERS OF TARGET COMPOUNDS }\end{array}$} \\
\hline Targets & Molecular weight & Parent ion $(\mathrm{m} / \mathrm{z})$ & Daughter ion $(\mathrm{m} / \mathrm{z})$ & $\mathrm{DP}(\mathrm{V})$ & $\mathrm{EP}(\mathrm{V})$ & $\mathrm{CE}(\mathrm{V})$ & CXP (V) \\
\hline \multirow{2}{*}{ Carbofuran } & 221.1 & 222.1 & $123.2^{\mathrm{a}}$ & 60 & 10 & 30 & 15 \\
\hline & & {$[\mathrm{M}+\mathrm{H}]^{+}$} & 165.1 & 60 & 10 & 18 & 15 \\
\hline \multirow[t]{2}{*}{ Fenobucarb } & 209.2 & 210.2 & $111.0^{\mathrm{a}}$ & 52 & 6 & 20 & 12 \\
\hline & & {$[\mathrm{M}+\mathrm{H}]^{+}$} & 168.1 & 52 & 6 & 11 & 12 \\
\hline \multirow[t]{2}{*}{ Isoprocarb } & 207.3 & 208.3 & $95.1^{\mathrm{a}}$ & 60 & 6 & 20 & 8 \\
\hline & & {$[\mathrm{M}+\mathrm{H}]^{+}$} & 152.1 & 60 & 6 & 12 & 12 \\
\hline \multirow[t]{2}{*}{ Mercaptodimethur } & 201.1 & 202.2 & $145.1^{\mathrm{a}}$ & 54 & 6 & 15 & 14 \\
\hline & & {$[\mathrm{M}+\mathrm{H}]^{+}$} & 127.1 & 54 & 6 & 40 & 11 \\
\hline \multirow[t]{2}{*}{ Aldicarb } & 193.1 & 194.0 & $95.1^{\mathrm{a}}$ & 59 & 7 & 35 & 18 \\
\hline & & {$[\mathrm{M}+\mathrm{H}]^{+}$} & 137.1 & 59 & 7 & 13 & 25 \\
\hline \multirow[t]{2}{*}{ Aldicarb-sulfoxide } & 165.1 & 166.1 & $109.1^{\mathrm{a}}$ & 55 & 6 & 15 & 21 \\
\hline & & {$[\mathrm{M}+\mathrm{H}]^{+}$} & 94.1 & 55 & 6 & 42 & 18 \\
\hline \multirow[t]{2}{*}{ Methomyl } & 225.3 & 226.2 & $169.1^{\mathrm{a}}$ & 60 & 7 & 14 & 12 \\
\hline & & {$[\mathrm{M}+\mathrm{H}]^{+}$} & 121.1 & 60 & 7 & 27 & 12 \\
\hline \multirow[t]{2}{*}{ Tebuconazole } & 237.2 & 238.2 & $220.1^{\mathrm{a}}$ & 66 & 6 & 9 & 20 \\
\hline & & {$[\mathrm{M}+\mathrm{H}]^{+}$} & 181.1 & 66 & 6 & 16 & 15 \\
\hline \multirow[t]{2}{*}{ Hexaconazole } & 190.1 & 213.0 & $116.1^{\mathrm{a}}$ & 50 & 10 & 16 & 10 \\
\hline & & {$[\mathrm{M}+\mathrm{Na}]^{+}$} & 89.0 & 50 & 10 & 23 & 8 \\
\hline \multirow[t]{2}{*}{ Carbofuran } & 222.2 & 223.2 & $148.1^{\mathrm{a}}$ & 65 & 6 & 13 & 13.5 \\
\hline & & {$[\mathrm{M}+\mathrm{H}]^{+}$} & 86.0 & 65 & 6 & 22 & 17 \\
\hline \multirow[t]{2}{*}{ Fenobucarb } & 206.2 & 229.2 & $166.1^{\mathrm{a}}$ & 50 & 10 & 16 & 12 \\
\hline & & {$[\mathrm{M}+\mathrm{Na}]^{+}$} & 132.0 & 54 & 6 & 10 & 12 \\
\hline \multirow[t]{2}{*}{ Isoprocarb } & 219.2 & 242.1 & $72.1^{\mathrm{a}}$ & 55 & 10 & 32 & 7 \\
\hline & & {$[\mathrm{M}+\mathrm{Na}]^{+}$} & 121.1 & 55 & 10 & 19 & 10 \\
\hline \multirow[t]{2}{*}{ Mercaptodimethur } & 162.2 & 163.1 & $88.0^{\mathrm{a}}$ & 45 & 7 & 14 & 9 \\
\hline & & {$[\mathrm{M}+\mathrm{H}]^{+}$} & 106.0 & 45 & 7 & 14 & 10 \\
\hline \multirow[t]{2}{*}{ Aldicarb } & 341.1 & 342.1 & $159.1^{\mathrm{a}}$ & 80 & 6 & 40 & 15 \\
\hline & & {$[\mathrm{M}+\mathrm{H}]^{+}$} & 69.1 & 80 & 6 & 36 & 13.5 \\
\hline \multirow[t]{2}{*}{ Aldicarb-sulfoxide } & 307.1 & 308.2 & $70.1^{\mathrm{a}}$ & 80 & 6 & 50 & 13.5 \\
\hline & & {$[\mathrm{M}+\mathrm{H}]^{+}$} & 125.1 & 80 & 6 & 50 & 12.5 \\
\hline \multirow[t]{2}{*}{ Methomyl } & 325.1 & 326.1 & $70.1^{\mathrm{a}}$ & 90 & 7 & 56 & 14 \\
\hline & & {$[\mathrm{M}+\mathrm{H}]^{+}$} & 159.1 & 90 & 7 & 45 & 16 \\
\hline \multirow[t]{2}{*}{ Tebuconazole } & 313.2 & 314.2 & $70.1^{\mathrm{a}}$ & 80 & 6 & 45 & 12 \\
\hline & & {$[\mathrm{M}+\mathrm{H}]^{+}$} & 159.0 & 80 & 6 & 45 & 12 \\
\hline \multirow[t]{2}{*}{ Hexaconazole } & 295.1 & 296.1 & $70.2^{\mathrm{a}}$ & 38 & 6 & 45 & 12 \\
\hline & & {$[\mathrm{M}+\mathrm{H}]^{+}$} & 279.1 & 27 & 6 & 7 & 20 \\
\hline \multirow[t]{2}{*}{ Carbaryl-D3 } & 204.1 & 205.2 & $145.1^{\mathrm{a}}$ & 54 & 6 & 14 & 14 \\
\hline & & {$[\mathrm{M}+\mathrm{H}]^{+}$} & 127.1 & 54 & 6 & 37 & 13 \\
\hline \multirow[t]{2}{*}{ Aldicarb-D3 } & 193.1 & 216.1 & $89.0^{\mathrm{a}}$ & 55 & 8 & 23 & 17 \\
\hline & & {$[\mathrm{M}+\mathrm{H}]^{+}$} & 116.1 & 55 & 8 & 17 & 23 \\
\hline Tebuconazole-D6 & 313.1 & 314.2 & $72.1^{\mathrm{a}}$ & 80 & 6 & 50 & 14 \\
\hline & & {$[\mathrm{M}+\mathrm{H}]^{+}$} & 125.1 & 80 & 6 & 50 & 14 \\
\hline Fluconazole-D4 & 310.2 & 311.2 & $242.2^{\mathrm{a}}$ & 72 & 6 & 23 & 16 \\
\hline & & {$[\mathrm{M}+\mathrm{H}]^{+}$} & 223.1 & 72 & 6 & 26 & 22 \\
\hline BDMC & 257.0 & 258.1 & $201.1^{\mathrm{a}}$ & 65 & 6 & 15 & 15 \\
\hline & & {$[\mathrm{M}+\mathrm{H}]^{+}$} & 122.2 & 65 & 6 & 30 & 12 \\
\hline
\end{tabular}

Column selection: Chromatographic column is one of the important parameters that influence on separation and retention of targets. This paper examines properties of separation and retention of the target utilizing X-bridge $\mathrm{C}_{18}$ column (Waters, $2.1 \mathrm{~mm} \times 3.5 \mu \mathrm{m} ; 150 \mathrm{~mm}$ ), X-bridge phenyl column (Waters, $2.1 \mathrm{~mm} \times 3.5 \mu \mathrm{m} ; 150 \mathrm{~mm}$ ) and carbamate dedicated analytical column (Waters, $3.9 \mathrm{~mm} \times 5 \mu \mathrm{m} ; 150 \mathrm{~mm}$ ). $\mathrm{C}_{18}$ column is widely used as reversed phase chromatographic column, Phenyl column be more helpful for the retention of polar compounds with weak polarity, Carbamate analytical column is specific object for separation and analysis of carbamate pesticides. The separation and retention of the targets on the three kinds of analytical columns are shown as in Fig. 2a, 2b and 2c, respectively. Most of the target objects has strong hold on $\mathrm{C}_{18}$ column (Fig 2a), their chromatographically peaks were sharp, symmetrical, but retentions of aldicarb-sulfone, aldicarbsulfoxide and oxamyl were more weaker and their chromatographic peak broadening, their mass response intensity is very poor. Fig. $2 \mathrm{~b}$ shows that capacity of retention and separation of the phenyl column for targets are very similar to $\mathrm{C}_{18}$ column, the peak width and analytical sensitive of aldicarb-sulfone, aldicarb-sulfoxide and oxamyl do not be improved. Fig. 3c indicates separation capable of carbamate special chromatographic column for the targets with high mass responds was best in all the column, especially that aldicarb-sulfone, aldicarbsulfoxide and oxamyl's peaks has more sharp, symmetry and 


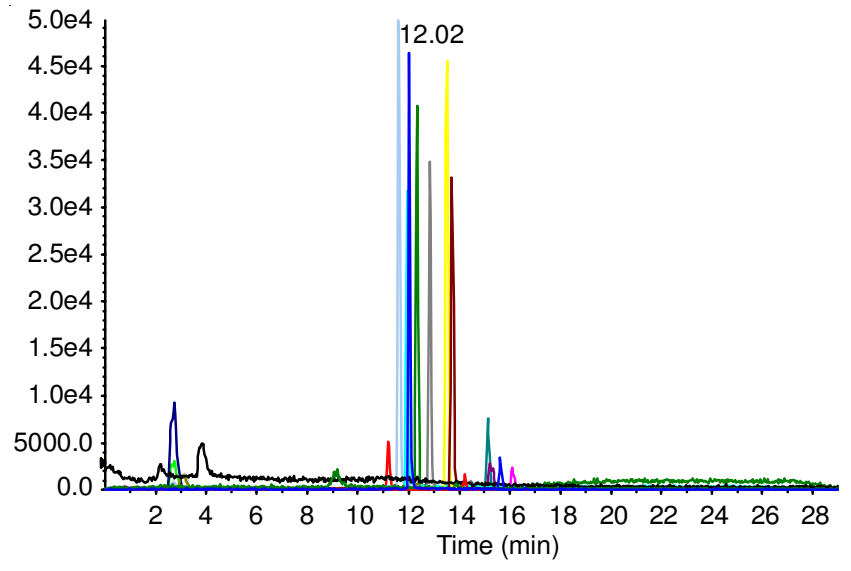

Fig. 2a. Retention of 18 carbamate and triazol pesticides on Waters $\mathrm{X}$-bridge $\mathrm{C}_{18}$ columns. $(2.1 \mathrm{~mm} \times 3.5 \mu \mathrm{m} ; 150 \mathrm{~mm})$

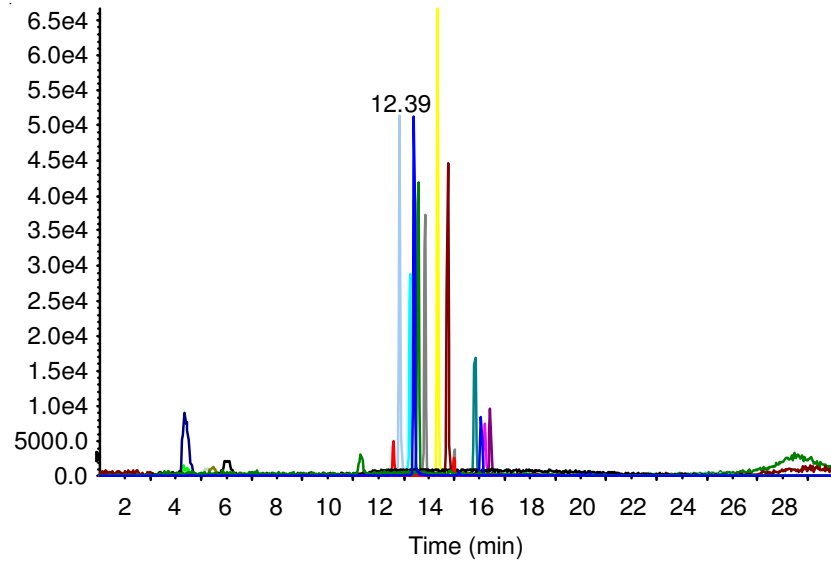

Fig. 2b. Retention of 18 carbamate and triazol pesticides on. Waters X-bridge phenyl columns. $(2.1 \mathrm{~mm} \times 3.5 \mu \mathrm{m} ; 150 \mathrm{~mm})$

and the analytical sensitivity were improved significantly. So the carbamate dedicated column was chosen as the analytical column of targets.

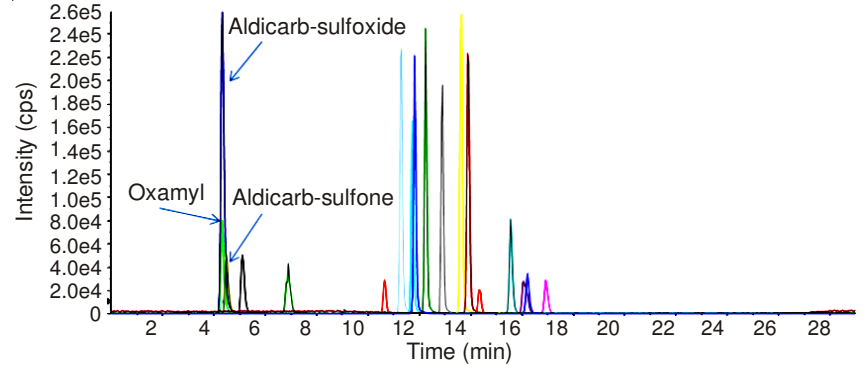

Fig. 2c. Retention of 18 carbamate and triazol pesticides. On carbamate special analytical column $(3.9 \mathrm{~mm} \times 5 \mu \mathrm{m} ; 150 \mathrm{~mm})$

MS parameters optimization: In multiple monitoring mode the mass parameters were optimized respectively and the optimal results were listed below Table-1. The optimal experimental was conducted on the liquid chromatography with flow injection (FIA) sampling. The ion source parameters of electrospray ionization voltage, ion source temperature (TEM), curtain gas (CUR), atomization gas (GS), heated auxiliary gas are also optimized. Fig 3 is chart of targets ionization efficiency at different ion source temperature.

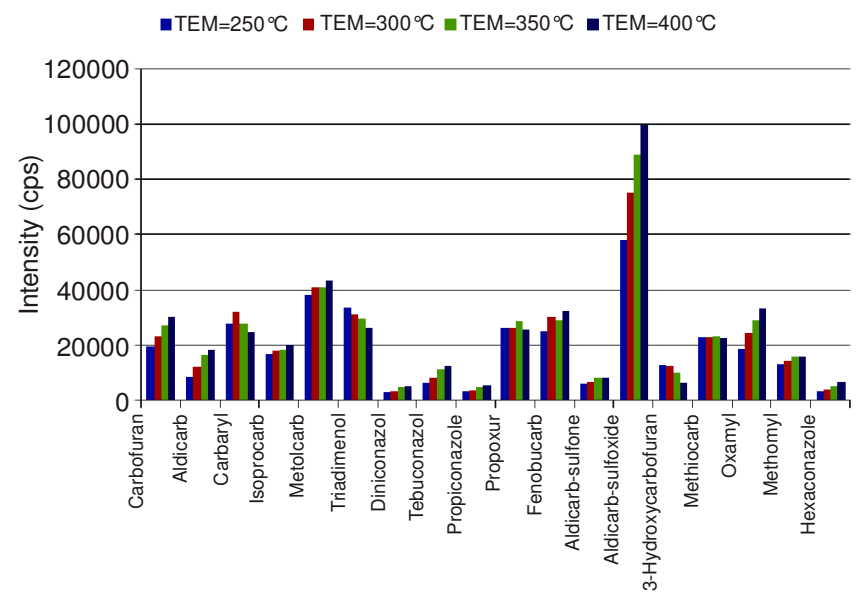

Fig. 3. Effect of ion source temperature on the ionization efficiency of target compounds

TABLE-2

LINEAR RANGES, REGRESSION EQUATION AND CORRELATION COEFFICIENTS ( ${ }^{2}$ ) OF TARGET COMPOUNDS

\begin{tabular}{ccccc}
\hline Target & Linear range $(\mu \mathrm{g} / \mathrm{L})$ & Linear equation & Correlation coefficient $\left(\mathrm{R}^{2}\right)$ & Method Detection Limits $(\mu \mathrm{g} / \mathrm{kg})$ \\
\hline Carbofuran & $0.1-100$ & $\mathrm{y}=0.9927 \mathrm{x}+0.0135$ & 0.9999 & 0.010 \\
Propoxur & $0.1-100$ & $\mathrm{y}=0.7924 \mathrm{x}-0.0095$ & 0.9991 & 0.020 \\
Fenobucarb & $0.1-100$ & $\mathrm{y}=1.4403 \mathrm{x}-0.0659$ & 0.9980 & 0.025 \\
Carbaryl & $0.1-100$ & $\mathrm{y}=1.0581 \mathrm{x}-0.0001$ & 0.9986 & 0.030 \\
Isoprocarb & $0.1-100$ & $\mathrm{y}=0.9545 \mathrm{x}-0.0239$ & 0.9996 & 0.020 \\
Metolcarb & $0.1-100$ & $\mathrm{y}=1.3277 \mathrm{x}-0.0528$ & 0.9989 & 0.060 \\
Mercaptodimethur & $0.1-20$ & $\mathrm{y}=0.8937 \mathrm{x}+0.0317$ & 0.9967 & 0.025 \\
3-Hydroxycarbofuran & $0.5-100$ & $\mathrm{y}=0.2795 \mathrm{x}-0.0284$ & 0.9958 & 0.120 \\
Aldicarb & $0.1-100$ & $\mathrm{y}=0.7502 \mathrm{x}-0.0321$ & 0.9997 & 0.025 \\
Aldicarb-sulfone & $0.1-10$ & $\mathrm{y}=0.2450 \mathrm{x}+0.0056$ & 0.9995 & 0.010 \\
Aldicarb-sulfoxide & $0.1-10$ & $\mathrm{y}=4.9287 \mathrm{x}+0.0418$ & 0.9997 & 0.030 \\
Oxamyl & $0.2-20$ & $\mathrm{y}=1.1285 \mathrm{x}-0.0068$ & 0.9987 & 0.075 \\
Methomyl & $0.2-10$ & $\mathrm{y}=0.4174 \mathrm{x}+0.0133$ & 0.9991 & 0.130 \\
Propiconazole & $0.1-100$ & $\mathrm{y}=0.8749 \mathrm{x}-0.1068$ & 0.9956 & 0.025 \\
Tebuconazole & $0.1-100$ & $\mathrm{y}=1.2944 \mathrm{x}-0.0881$ & 0.9981 & 0.015 \\
Diniconazole & $0.1-100$ & $\mathrm{y}=0.4856 \mathrm{x}-0.0701$ & 0.9954 & 0.040 \\
Hexaconazole & $0.1-100$ & $\mathrm{y}=0.5812 \mathrm{x}-0.0481$ & 0.9967 & 0.035 \\
Triadimenol & $0.1-100$ & $\mathrm{y}=0.2806 \mathrm{x}-0.0021$ & 0.9961 & 0.015
\end{tabular}

$\mathrm{x}$. The target concentration/internal standard concentration, $\mathrm{y}$. The target peak area/internal standard peak area 


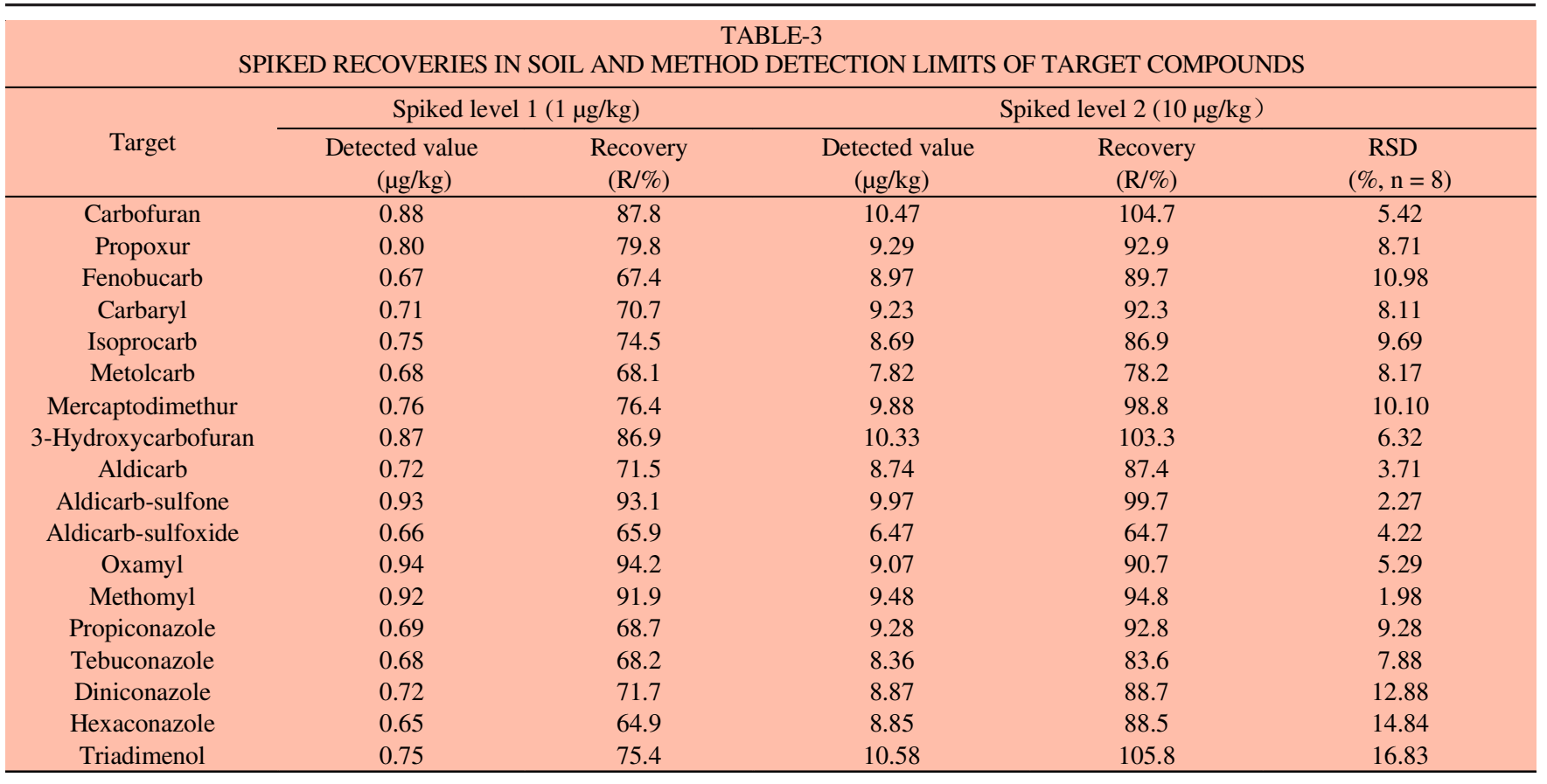

Method validation: Prepared five concentration levels targets standards with internal standards and surrogates standards at a concentration of $10 \mu \mathrm{g} \mathrm{L}^{-1}$, then deterrmined by LC-MSMS under the optimized analysis conditions. The linear range, the linear correlation coefficient and regression equations obtained are shown in Table-2. The results show that in addition to aldicarb-sulfone, aldicarb-sulfoxide and methomyl linear range of 0.1-10 $\mu \mathrm{g} \mathrm{L}^{-1}$, methiocarb, oxamyl linear range of 0.1-20 $\mu \mathrm{g} \mathrm{L}^{-1}$, the other targets the linear range were between $0.1-100 \mu \mathrm{g} \mathrm{L}{ }^{-1}$, the linear correlation coefficient $\mathrm{R}^{2}$ of all targets were greater than 0.995 . The targets spiked recoveries and precisions are listed in Table-3. The results showed that recoveries matrix spiked at $1 \mu \mathrm{g} \mathrm{kg}^{-1}$ and $10 \mu \mathrm{g} \mathrm{kg}^{-1}$ ranged from 64.9 to $94.2 \%$ and 64.7 to $104.7 \%$, respectively and relative standard deviations (RSDs) ranged between 1.98 to $16.43 \%$ $(\mathrm{n}=8)$ with method detection limits ranged from $0.010 \mu \mathrm{g}$ $\mathrm{kg}^{-1}$ to $0.130 \mu \mathrm{g} \mathrm{kg}^{-1}$.

Determination of real soil samples: The optimized procedure was applied to analyze carbamate and their degradation products and triazole pesticide in soil that collected from grass, watermelon field, wheat field and peach orchard soil near to suburban areas of Beijing. The propoxur and triadimenol were detected in all samples with the concentration of propoxur in range of $0.23-0.42 \mu \mathrm{g} \mathrm{kg}^{-1}$ and triazole alcohols range between $0.01-0.17 \mu \mathrm{g} \mathrm{kg}^{-1}$. The ablealdicarb were also found in watermelon field and wheat field with at the concentration of 0.09 $0.12 \mu \mathrm{g} \mathrm{kg}^{-1}$ and higher diniconazole was detected in grass at the concentration of $5.08 \mu \mathrm{g} \mathrm{kg}^{-1}$, therefore it is an important to monitor pesticides residues of carbamate and triazole in soil.

\section{Conclusion}

The soil QuEChERS method established is simple, economical, fast and suitable for the sample preparation of thermally labile organic pollutants and provides a new way for the large numbers of soil sample analysis.

The analytical method using LC-MS MS in multiple monitor mode may overcomes the defects that carbamate and their degradation products need be derived, low sensitivity, matrix interference and thermal degradation using HPLC or GC for determination of targets in soil. The method detection limits ranged from 0.010 to $0.130 \mu \mathrm{g} \mathrm{kg}^{-1}$ with recoveries matrix spiked ranging from 64.9 to $94.2 \%$ and 64.7 to $104.7 \%$ at $1 \mu \mathrm{g} \mathrm{kg}^{-1}$ and $10 \mu \mathrm{g} \mathrm{kg}^{-1}$, respectively, meanwhile relative standard deviations (RSDs) ranging between 1.98 to $16.43 \%$ $(\mathrm{n}=8)$. The method established is sensitive, accurate, rapid, effective, rugged and safe.

\section{ACKNOWLEDGEMENTS}

The authors are thankful to financial support received from Non-Profit Scientific Research Special Program of Ministry of Land and Resources (200911043-28) and the National Geological Survey Program in China (1212011220943, 1212010816028).

\section{REFERENCES}

1. D. Pimentel and L. Levitan, Bioscience, 36, 86 (1986)

2. http://edis.ifas.ufl.edu/pi088.

3. http://edis.ifas.ufl.edu/pi105.

4. R.M. González-Rodríguez, R. Rial-Otero, B. Cancho-Grande and J. Simal-Gándara, J. Chromatogr. A, 1196, 100 (2008).

5. G. Zhao, C. Wang, Q. Wu and Z. Wang, Anal. Methods, 3, 1410 (2011).

6. M.H. El-Saeid and M.T. Selim, J. Chem., Article ID 727149 (2013).

7. M.G.D. Silva, A. Aquino, H.S. Dórea and S. Navickiene, Talanta, 76, 680 (2008).

8. H. Chen, R.W. Chen and S.Q. Li, J. Chromatogr. A, 1217, 1244 (2010).

9. Q.-B. Lin, Y.-Y. Xue and H. Song, J. Chromatogr. Sci., 48, 7 (2010).

10. G. Vukovic', D. Shtereva, V. Bursic', R. Mladenova and S. Lazic', LWTFood Sci. Technol., 49, 312 (2012).

11. P. Deme, T. Azmeera, S. Kanjilal, P. Jonnalagadda and V.S. Upadhyayula, Food Anal. Methods, 6, 1162 (2013).

12. M. Anastassiades, S.J. Lehotay, D. Štajnbaher and F. Schenck, J. AOAC Int., 86, 412 (2003).

13. S. Lehotay, J. AOAC Int., 90, 485 (2007).

14. A. Wilkowska and M. Biziuk, Food Chem., 125, 803 (2011).

15. S. Juliana, M.G. Ferronato, L.C. Ribeiro, M.L. Martins, M.B. Adaime and R. Zanella, Talanta, 116, 827 (2013).

16. M.M. Rahman, J.H. Park, A.M. Abd El-Aty, J.H. Choi, H.R. Bae, A. Yang, K.H. Park and J.H. Shim, Biomed. Chromatogr., 27, 416 (2013). 